\title{
Evaluating legume species as alternative trap crops to chickpea for management of Helicoverpa spp. (Lepidoptera: Noctuidae) in central Queensland cotton cropping systems
}

\author{
P.R. Grundy ${ }^{1 *}$, R.V. Sequeira ${ }^{2}$ and K.S. Short ${ }^{1}$ \\ ${ }^{1}$ Plant Science, Department of Primary Industries and Fisheries, \\ LMB 1, Biloela, Queensland, 4715, Australia: ${ }^{2}$ Plant Science, \\ Department of Primary Industries and Fisheries, LMB 6, Emerald, \\ Queensland, 4720, Australia
}

\begin{abstract}
Mounting levels of insecticide resistance within Australian Helicoverpa spp. populations have resulted in the adoption of non-chemical IPM control practices such as trap cropping with chickpea, Cicer arietinum (L.). However, a new leaf blight disease affecting chickpea in Australia has the potential to limit its use as a trap crop. Therefore this paper evaluates the potential of a variety of winter-active legume crops for use as an alternative spring trap crop to chickpea as part of an effort to improve the area-wide management strategy for Helicoverpa spp. in central Queensland's cotton production region. The densities of Helicoverpa eggs and larvae were compared over three seasons on replicated plantings of chickpea, Cicer arietinum (L.), field pea Pisum sativum (L), vetch, Vicia sativa (L.) and faba bean, Vicia faba (L.). Of these treatments, field pea was found to harbour the highest densities of eggs. A partial life table study of the fate of eggs oviposited on field pea and chickpea suggested that large proportions of the eggs laid on field pea suffered mortality due to dislodgment from the plants after oviposition. Plantings of field pea as a replacement trap crop for chickpea under commercial conditions confirmed the high level of attractiveness of this crop to ovipositing moths. The use of field pea as a trap crop as part of an areawide management programme for Helicoverpa spp. is discussed.
\end{abstract}

\section{Introduction}

Helicoverpa armigera Hübner and $H$. punctigera Wallengren (Lepidoptera: Noctuidae) are serious pests of cotton in Australia (Fitt, 1994, 2000). Grower estimates put the typical cost of insect control on cotton in excess of $\mathrm{A} \$ 500 \mathrm{ha}^{-1}$ with insecticides used for Helicoverpa spp. management comprising the bulk of this cost (Macpherson \& Coulton, 2000). Despite increased adoption of integrated pest management (IPM) techniques such as biological and target-

*Fax: 0749923468

E-mail: Paul.Grundy@dpi.qld.gov.au specific insecticides, and various cultural control tactics, Australian cotton production still relies primarily on chemical insecticides for control of Helicoverpa spp. (Fitt, 1994, 2000). This pesticide dependence has led to the development of $H$. armigera populations that are highly resistant to commonly used insecticides (Forrestor et al., 1993; Gunning, 1994).

Increasing levels of insecticide resistance and rising costs of field control in cotton crops during the 1990s prompted a significant shift in the Helicoverpa spp. control strategy, away from individual field-based insecticide applications to a season long area-wide basis. Two studies on the population dynamics of Helicoverpa spp. spanning a period from 
1996-2001 in central Queensland suggested that Helicoverpa spp. abundance is largely driven by patterns of crop succession and resultant population exchanges that occur at key times between cotton and grain crops within the cropping region (Sequeira, 2001; Sequeira \& Playford, 2001). The pattern of Helicoverpa spp. recruitment strongly suggested that large populations of Helicoverpa spp. were cycling between winter rain fed and summer irrigated components of the central Queensland cropping system. The proposed pattern of cyclical population dynamics is also supported by analyses of inter-seasonal genetic shifts at the regional level in central Queensland (Scott et al., 2003).

An area-wide management (AWM) strategy was proposed for central Queensland in an effort to limit the rate of in-crop Helicoverpa spp. recruitment and exchange between cropping systems (Sequeira, 2001; Sequeira \& Playford, 2001, 2002). Part of the area-wide management strategy for central Queensland has involved the implementation of a trap cropping programme that aims to divert and capture Helicoverpa spp. during early spring and late summer when these populations would typically experience bottlenecks in host-plant availability associated with the transition between crops, seasons or both (Sequeira, 2001). Cotton growers plant approximately $1-2 \%$ of their total crop area to a trap crop of chickpea, Cicer arietinum (L.) in late winter and pigeon pea, Cajanus cajan (L.) (Fabaceae) in summer, both timed to coincide with key periods during which significant population exchange has been observed to occur between cotton and grain crops (Sequeira, 2001). After attracting large populations of Helicoverpa spp. larvae and pupae, the trap crops are destroyed by slashing and cultivation

The overall impacts of this area-wide strategy will not become apparent until its has gone through several implementation cycles. Data collection aimed at quantifying the programme's impact has been underway since its initial implementation (Sequeira, 2001). The immediate focus is to maximize the functional efficiency of the strategy's components.

A problem since encountered with using chickpea as a spring trap crop is its susceptibility to leaf blight disease caused by the pathogen Ascochyta rabiei (Pass.) (teleomorph Didymella rabiei, Mycosphaerellaceae). This seed-borne pathogen has recently spread throughout southern Australia and caused serious disease epidemics in commercial chickpeas (Khan et al., 1999). To date, central Queensland is one of the few remaining regions still free of this disease, however the growing of chickpeas as trap crops presents a potential risk in terms of disease introduction or providing additional point sources for infection.

To address this problem, a number of winter active legumes were evaluated for their attractiveness to Helicoverpa spp. in an attempt to identify an alternative to chickpea that could be used for spring trap cropping in central Queensland. An alternative legume may also have application in southern Australian regions where A. rabiei is established and poses a problem with the use of chickpea for trap cropping.

\section{Materials and methods}

\section{Comparative assessment of legume species}

\section{Host choice assessment}

Two experiments were conducted within a 20 ha field of wheat, Triticum aestivum (L.) cv. Kennedy (Gramineae) near the township of Biloela, central Queensland $\left(24^{\circ} 22^{\prime} \mathrm{S}\right.$, $150^{\circ} 06^{\prime} \mathrm{E}$ ) during the winter and spring of 2001 and 2002. In each experiment, treatment plots with dimensions $20 \mathrm{~m} \times$ $20 \mathrm{~m}$ and $1 \mathrm{~m}$ row spacing were arranged in a randomized block design with four replicates of each treatment. The plots were separated by $15 \mathrm{~m}$ buffer strips sown to wheat on all sides. In the 2001 experiment, legume (Fabaceae) treatments of chickpea cv. Amethyst, field peas, Pisum sativum (L.) cv. Alma and two varieties of vetch, Vicia sativa (L.) cvs Namoi and Popani were compared. In the 2002 experiment, comparisons were made between treatments of chickpea cv. Amethyst, field pea cv. Alma and faba beans, Vicia faba (L.) cv. Fiord. The plots and buffers were planted on 26 June 2001 and 4 July 2002.

In the early crop stages, sampling for Helicoverpa spp. was done at approximate 10-day intervals. The sampling frequency was increased once Helicoverpa spp. activity was observed to increase in the treatment plots. The data were expressed as numbers of insects $\mathrm{m}^{-1}$ for each treatment.

Helicoverpa armigera was the dominant species, with only low numbers $(<30 \%)$ of $H$. punctigera observed each season. Visual counts of Helicoverpa spp. eggs and larvae were made on two separate sets of randomly selected 1-m lengths of crop foliage in each treatment replicate. When sampling for eggs, four 1-m lengths of foliage was cut from each plot and returned to a field laboratory for close inspection. A beat sheet sampling method was used to assess the densities of Helicoverpa spp. larvae on four 1-m lengths of foliage. The sheet was $1.5 \mathrm{~m}$ wide by $2 \mathrm{~m}$ long and made from yellow canvas. A $25 \mathrm{~mm}$ diameter piece of timber dowel $(1.5 \mathrm{~m}$ long) was fixed to each end of the sheet to prevent the ends lifting in the wind. Samples were taken by placing the sheet behind the legume plants to be sampled, along the inter-row and up over the adjacent row of foliage to create a 'wall' to catch insects. A 1-m long stick was then used to shake $1 \mathrm{~m}$ of row onto the sheet for assessment. The legume foliage was shaken several times from the base of the plants to the top. The number of larvae was then assessed before being returned to the foliage from which they were sampled.

The treatment plots were destroyed by cultivation on 3 and 9 October respectively for the 2001 and 2002 experiments.

\section{Impact of host choice on survival}

The fate of eggs laid on chickpea and field pea (these two treatments were chosen because eggs were the most abundant) was investigated during each experiment using methods similar to those described by Titmarsh (1992). White eggs were individually tagged and revisited each day over a period of one week to determine survivorship through the egg and early larval stages. A total of 960 white eggs (60 in each treatment replicate in each experiment) were monitored. The positions of individual eggs were recorded by marking the adjacent leaf surface with a fine tipped, non-toxic pilot felt pen. The corresponding leaf node or branch was also flagged with coloured tape to allow ease of location each day.

\section{On-farm evaluation of trap crops}

Following the 2001 experiment, field pea were substituted for chickpea as the trap crop in several locations in central Queensland to compare Helicoverpa spp. activity under commercial conditions. 
In the 2002 season, two trap crops of field peas were planted in the last week of June in the cotton irrigation area surrounding the township of Theodore $\left(24^{\circ} 55^{\prime} \mathrm{S}, 149^{\circ} 58^{\prime} \mathrm{E}\right)$. In 2003, three trap crops of field peas were planted during the last week of June and first week of July. The trap crops were planted in an area of 2-3 ha at each site. Helicoverpa spp. abundance on these field pea trap crops was compared with nearby chickpea trap crops also planted on 2-3 ha fields in the same region, all within a radius of $15 \mathrm{~km}$.

Visual counts of Helicoverpa spp. eggs and larvae were made on four randomly selected 1-m lengths of foliage in each trap crop using the methods described above. Beneficial insects were also surveyed at the same time. Samples were taken every $4-8$ days. Data were expressed as larvae and eggs $\mathrm{m}^{-1}$.

\section{Analysis of data}

The count data from each experiment and farm evaluation studies for Helicoverpa eggs and larvae at each sampling date were analysed using a repeated measurements analysis using the method of residual maximum likelihood (REML) with antedependence covariate structure of order 1 with the Genstat computer program (Payne et al., 1989). This model was used to assess treatment by time interactions. The egg survival data was subject to ANOVA using the Genstat program, and least significant differences were calculated to determine treatment differences at $P<0.05$.

\section{Results \\ Comparative assessment of legume species}

Host choice assessment

Field peas attracted significantly higher $(P<0.01)$ numbers of eggs of Helicoverpa spp. than all other treatments including chickpea in the 2001 assessment (fig. 1) whilst there were no significant differences in the density of eggs between the two vetch treatments. This trend was repeated in the 2002 assessment wherein field peas attracted

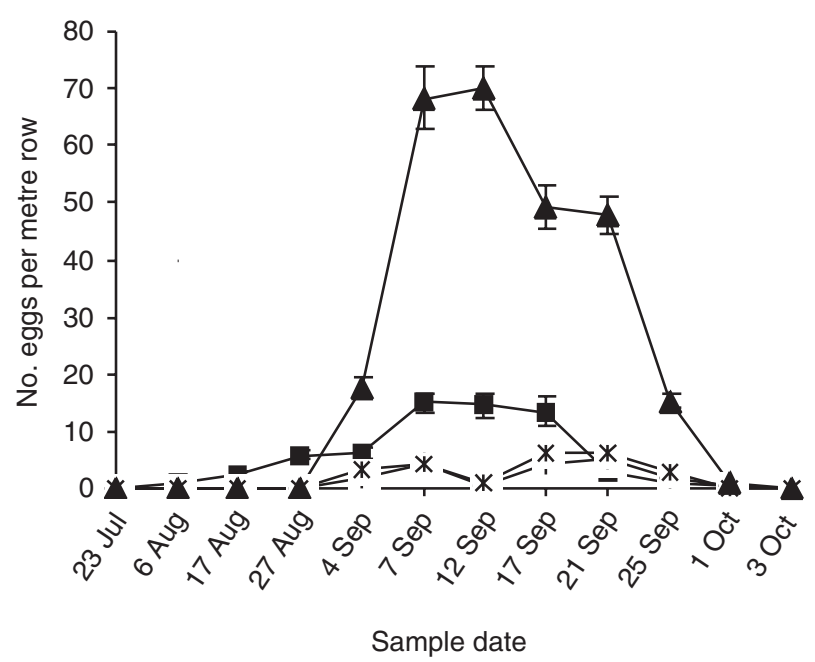

Fig. 1. Helicoverpa eggs per $\mathrm{m}^{-1}$ of crop foliage in the treatment plots of chickpea $(\boldsymbol{\square})$, popani vetch $(+)$, namoi vetch $(*)$ and field pea $(\boldsymbol{\Delta})$ in the 2001 legume assessment. Error bars denote s.e.m. significantly higher $(P<0.01)$ numbers of eggs than the chickpea and faba bean treatments (fig. 2).

In contrast, larval densities of Helicoverpa spp. were significantly higher $(P<0.01)$ in chickpea compared to the other treatment legumes in 2001 with the same significant trend $(P<0.01)$ repeated in 2002 (figs 3 and 4$)$. The density of Helicoverpa spp. larvae was also significantly higher in field pea compared to the two vetch varieties in 2001 and significantly higher than the densities recorded in faba bean treatments during 2002 (figs 3 and 4).

In both experiments few Helicoverpa spp. eggs were observed on field pea plants prior to anthesis. In contrast, eggs were observed on chickpea plants prior to flowering.

\section{Impact of host choice on survival}

A large number of the tagged eggs disappeared from the plants, particularly in the field pea treatment. The eggs or resultant neonates that disappeared from the plants could not be accounted for either as cadavers or by the appearance of other individuals. The percentage of eggs unaccounted for and therefore presumed dead in the field peas was significantly $(P<0.01)$ greater than in chickpeas in both assessments (fig. 5).

\section{On-farm evaluation of trap crops}

When planted as a trap crop under commercial conditions field pea attracted significantly higher numbers $(P<0.01)$ of Helicoverpa spp. eggs compared with chickpeas during the 2002 and 2003 seasons (figs 6 and 7). Helicoverpa spp. oviposition in the field pea plots was observed primarily after the onset of anthesis. Field peas were also observed to host various coccinellid and neuropteran species, unlike chickpeas which did not host any beneficial insect species.

\section{Discussion}

A major proportion of Helicoverpa spp. immatures that develop within field crops die, with much of the mortality

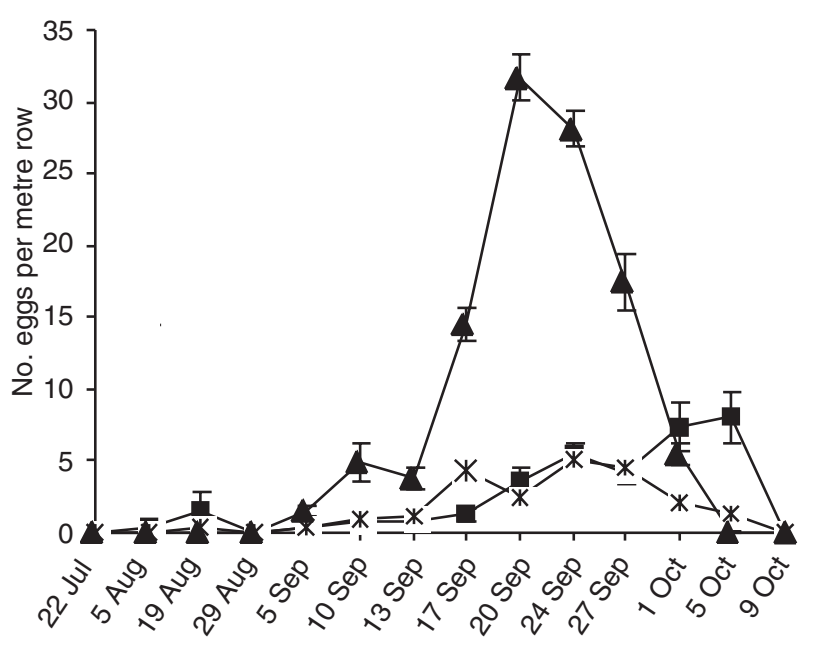

Sample date

Fig. 2. Helicoverpa eggs per $\mathrm{m}^{-1}$ of crop foliage in the treatment plots of chickpea $(\boldsymbol{\square})$, faba bean (*) and field pea $(\boldsymbol{\Delta})$ for the 2002 legume assessment. Error bars denote s.e.m. 


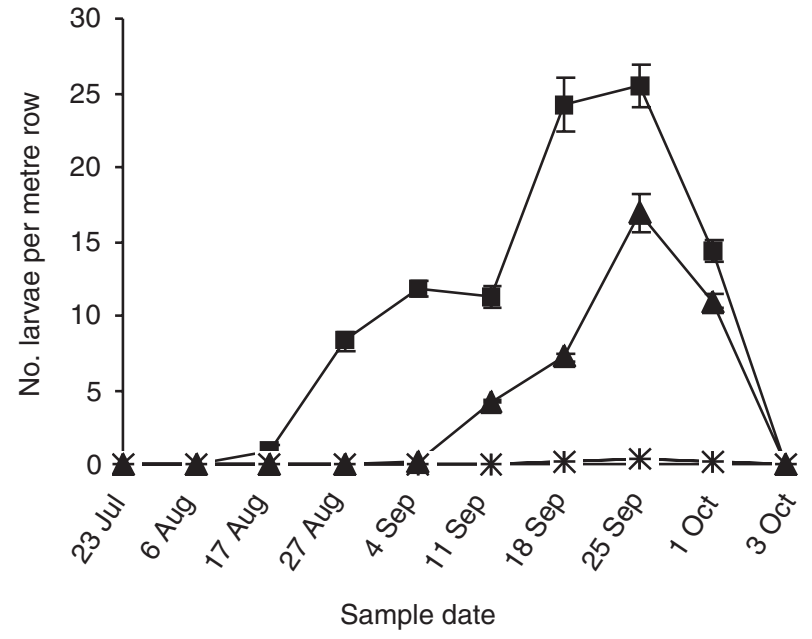

Fig. 3. Helicoverpa larvae per $\mathrm{m}^{-1}$ of crop foliage in the treatment plots of chickpea $(\boldsymbol{\square})$, popani vetch $(+)$, namoi vetch $(*)$ and field pea $(\boldsymbol{\Delta})$ for the 2001 legume assessment. Error bars denote s.e.m.

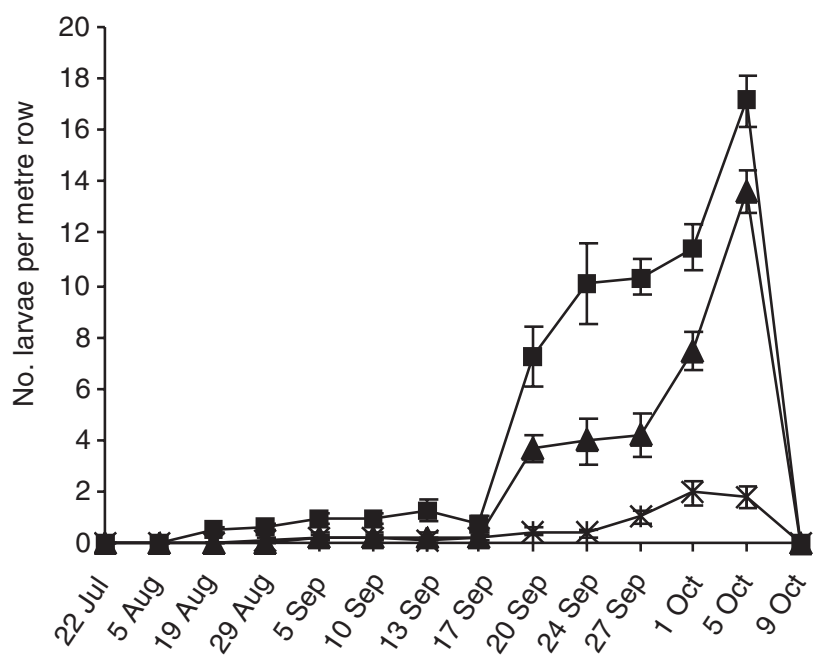

Sample date

Fig. 4. Helicoverpa larvae per $\mathrm{m}^{-1}$ of crop foliage in the treatment plots of chickpea (ם), faba bean (*) and field pea (A) for the 2002 legume assessment. Error bars denote s.e.m.

believed to occur during the early life stages (Fitt, 1989). These suspected losses were investigated and verified by Titmarsh (1992) who found that most of the mortality affecting Helicoverpa spp. in field crops occurs prior to the third-instar stage.

During each experiment, field pea attracted higher levels of egg laying activity by Helicoverpa spp. than the other legume treatments, although this did not correspond with significantly higher larval numbers. Upon hatching Helicoverpa spp. larvae typically consume part or all of the eggshell except for the base which remains adhered to the foliage surface (Waterhouse \& Norris, 1987; Reed, 1989). The presence of this residual shell was used during tagging observations to determine whether or not the eggs had

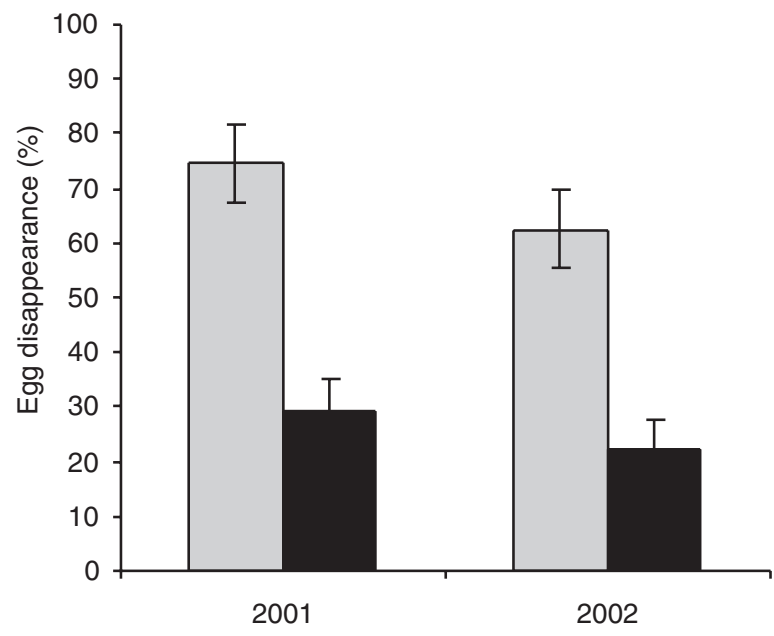

Fig. 5. Disappearance (presumed mortality) of marked Helicoverpa eggs from the chickpea ( $\square$ ) and field pea $(\square)$ plots during the 2001 and 2002 legume assessments. Error bars denote s.e.m.

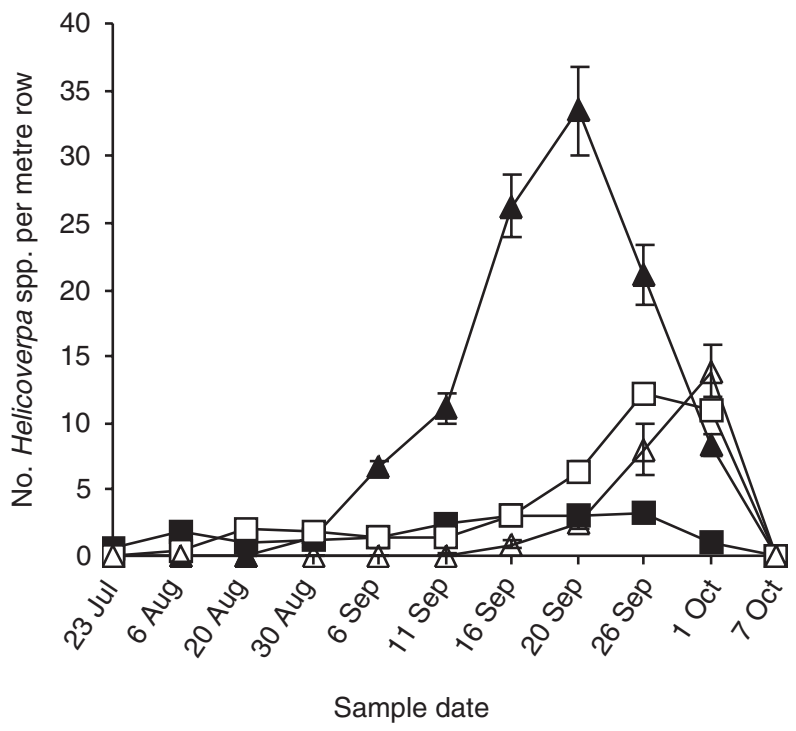

Fig. 6. Helicoverpa eggs and larvae per $\mathrm{m}^{-1}$ of crop foliage in the chickpea and field pea trap crop fields at Theodore 2002. Error bars denote s.e.m. $\mathbf{\square}$, Eggs on chickpea; $\boldsymbol{\Lambda}$, eggs on field pea; $\square$, larvae on chickpea; $\triangle$, larvae on field pea.

hatched. In the absence of a residual shell or neonate larvae within close proximity to the marked site, the eggs were assumed to have been dislodged prior to hatching.

A much greater proportion of eggs was observed to have been dislodged from the field peas compared to chickpeas during the 2001 and 2002 assessments (fig. 5). The higher levels of egg retention observed in chickpea may partly explain why this legume carried higher densities of larvae compared to field pea.

Dislodgement of eggs from field pea may be largely due to the waxy nature of the leaves. During the collection and handling of field pea foliage for egg sampling, many of the Helicoverpa spp. eggs were observed to readily dislodge, something that was not observed in chickpeas. 


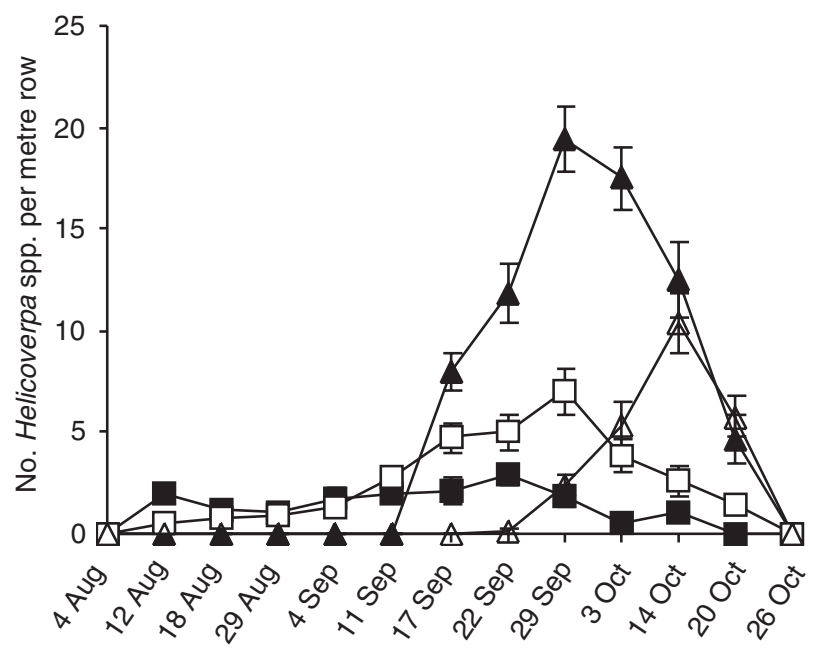

Sample date

Fig. 7. Helicoverpa eggs and larvae per $\mathrm{m}^{-1}$ of crop foliage chickpea and field pea trap crop fields at Theodore 2002. Error bars denote s.e.m. $\mathbf{\square}$, Eggs on chickpea; $\boldsymbol{\Lambda}$, eggs on field pea; $\square$, larvae on chickpea; $\triangle$, larvae on field pea.

The use of trap crops as part of the area-wide management programme for Helicoverpa spp. in central Queensland since 1997 has been conceptually attractive as an insecticide resistance management tool for concentrating this pest into small areas where it can be destroyed mechanically (Sequeira \& Playford, 2001). In this way, the trap crops serve as sinks for a proportion of the progeny of immigrating or emigrating egg-laying moths. In these experiments field pea acted as a superior sink in terms of capturing a greater proportion of moth progeny than chickpea. This trend was replicable when field pea was substituted for chickpea as the trap crop within the Theodore cotton irrigation area, again demonstrating the attractiveness of this crop to ovipositing Helicoverpa spp. moths.

The substitution of field pea for chickpea as a spring trap crop in central Queensland is advantageous in that it circumvents potential problems with leaf blight caused by A. rabiei that continues to threaten the disease-free status of central Queensland's commercial chickpea industry. Field pea is also advantageous compared to chickpea which can frequently serve as a Helicoverpa spp. nursery by hosting substantial populations during the early vegetative stages under central Queensland conditions. These early populations in chickpea often require chemical control to prevent dispersal.

These results show that field pea is highly attractive to Helicoverpa spp. moths in spring after the onset of anthesis. Unlike chickpea, many of the eggs laid on field pea perish which in part makes it a self-sustaining trap crop during the first weeks of becoming attractive to Helicoverpa spp. Field pea was also observed to host various predatory arthropods which could potentially disperse into surrounding cotton crops upon trap crop destruction.

The use of field pea in southern regions for spring trap cropping may also have merit and warrants investigation. If successful under cooler conditions, the use of field pea would also ease the management of trap crops in these regions by eliminating the current need to apply several fungicides for the control of $A$. rabiei.

Data collection to validate the expected outcomes of the area-wide management programme has been underway since its inception and implementation in 1997. Sequeira (2001) attempted a limited qualitative assessment of the programme's impacts over a four-year period. This analysis showed that whilst changes in the population dynamics and in-field infestation levels in cotton crops were evident since the implementation of the programme in 1997, these changes could not be attributed completely and unequivocally to the programme. Several factors over the last few seasons including successive severe droughts and the introduction of transgenic Bt cottons (Ingard ${ }^{\circledR}$ ) for $30 \%$ of the irrigation cropping area make it difficult to distinguish the impact of the area-wide programme from that of environmental factors and cropping practices on Helicoverpa spp. population dynamics in the region. Future analyses will address this issue in greater detail. The use of field pea as the preferred spring trap crop wherever possible will improve the implementation of the area-wide programme. This, in turn, should enhance the contribution of the strategy to Helicoverpa spp. management in the region.

\section{Acknowledgements}

The authors would sincerely like to thank Nicole PurvisSmith and Les Redman (QDPI) who assisted with planting, sampling and egg recording during the experiments. We would also thank Christina Playford (QDPI) for statistical advice. This research was financially supported by the Cotton Research and Development Corporation (Projects DAQ95C \& DAQ122C).

\section{References}

Fitt, G.P. (1989) The ecology of Heliothis species in relation to agroecosystems. Annual Review of Entomology 34, 17-52.

Fitt, G.P. (1994) Cotton pest management. Part 3: an Australian perspective. Annual Review of Entomology 39, 543-562.

Fitt, G.P. (2000) An Australian approach to IPM in cotton: integrating new technologies to minimise insecticide dependence. Crop Protection 19, 793-800.

Forrestor, N.W., Cahill, C., Bird, L.J. \& Layland, J.K. (1993) Management of pyrethroid and endosulfan resistance in Helicoverpa armigera (Hübner) (Lepidoptera: Noctuidae) in Australia. Bulletin of Entomological Research Supplemental Series, No 1.

Gunning, R.V. (1994) Resistance increasing in unsprayed populations of Helicoverpa armigera (Hübner) (Lepidoptera: Noctuidae) in New South Wales 1987-90. Journal of the Australian Entomological Society 33, 381.

Khan, M.S.A., Ramsey, M.D., Corbiere. R, Infantino, A., PortaPuglia, A., Bouznad, Z. \& Scott, E.S. (1999) Ascochyta blight of chickpea in Australia: identification, pathogenicity and mating type. Plant Pathology 48, 230-234.

Macpherson, I. \& Coulton, D. (2000) Definition of area wide management 1999-2000. Proceedings of the Tenth Australian Cotton Conference pp.45-50. Brisbane Queensland. Australian Cotton Growers Research Association, Wee Waa.

Payne, R., Lane, P.W., Ainsley, A.E., Bicknell, K,E., Digby, P.G.N., Harding, S.A., Leech, P.R., Simpson, R., Todd, 
A.D., Verrier, P.J. \& White, R.P. (1989) Genstat 5 Reference Manual. Oxford, Clarendon Press.

Reed, W. (1989) Measuring and modelling the effects of natural enemies on Heliothis spp. populations. pp. 33-35 in King, E.G. \& Jackson, R.D. (Eds) Proceedings of the Workshop on Biological Control of Heliothis: Increasing the effectiveness of natural enemies. Far Eastern Regional Research Office, US Department of Agriculture, New Dehli, India.

Scott, K.D., Wilkinson, K.S., Merritt, M.A., Scott, L.J., Lange, C.L., Schutze, M.K., Ketn, J.K., Merritt, D.J., Grundy, P.R. \& Graham, G.C. (2003) Genetic shifts in Helicoverpa armigera Hübner (Lepidoptera: Noctuidae) over a year in the Dawson/Callide valleys. Australian Journal of Agricultural Research 54, 739-744.

Sequeira, R. (2001) Inter-seasonal population dynamics and cultural management of Helicoverpa spp. in a central Queensland cropping system. Australian Journal of Experimental Agriculture 41, 249-259.

Sequeira, R. \& Playford, C. (2001) Abundance of Helicoverpa (Lepidoptera: Noctuidae) pupae under cotton and other crops in central Queensland: implications for resistance management. Australian Journal of Entomology 40, 264-269.

Sequeira, R. \& Playford, C. (2002) Trends in Helicoverpa spp. in (Lepidoptera: Noctuidae) abundance on commercial cotton in central Queensland: implications for pest management. Australian Journal of Experimental Agriculture 21, 439-447.

Titmarsh, I.J. (1992) Mortality of immature Lepidoptera. PhD thesis, Department of Entomology, University of Queensland, St Lucia, Australia.

Waterhouse, D.F. \& Norris, K.R. (1987) Biological control: Pacific prospects. Melbourne, Inkata Press.

(Accepted 10 July 2004)

(C) The State of Queensland (Department of Primary Industries) 2004 